\title{
Modeling a Virtual World for the Educational Game Calangos
}

\author{
Angelo C. Loula, ${ }^{1}$ Leandro N. de Castro, ${ }^{2}$ Antônio L. Apolinário Jr., ${ }^{3}$ Pedro L. B. da Rocha, ${ }^{4}$ \\ Maria da Conceição L. Carneiro, ${ }^{5}$ Vanessa Perpétua G. S. Reis, ${ }^{5}$ Ricardo F. Machado, ${ }^{6}$ \\ Claudia Sepulveda, ${ }^{7}$ and Charbel N. El-Hani ${ }^{8}$
}

${ }^{1}$ Intelligent and Cognitive Systems Lab, State University of Feira de Santana, 44036-900 Feira de Santana, BA, Brazil

${ }^{2}$ Natural Computing Laboratory, Mackenzie Presbyterian University, 01302-090 São Paulo, SP, Brazil

${ }^{3}$ Computer Science Department, Federal University of Bahia, 40170-290 Salvador, BA, Brazil

${ }^{4}$ Laboratory of Terrestrial Vertebrates, Institute of Biology, Federal University of Bahia, 40170-290 Salvador, BA, Brazil

${ }^{5}$ Institute of Education Gastão Guimarães, 44026010 Feira de Santana, BA, Brazil

${ }^{6}$ Graduate Studies Program in History, Philosophy and Science Teaching, Federal University of Bahia and State University of Feira de Santana, 44036-900 Feira de Santana, BA, Brazil

${ }^{7}$ Department of Education, State University of Feira de Santana, 44036-900 Feira de Santana, BA, Brazil

${ }^{8}$ Institute of Biology, Federal University of Bahia, 40170-290 Salvador, BA, Brazil

Correspondence should be addressed to Angelo C. Loula; angelocl@uefs.br

Received 7 November 2013; Revised 20 February 2014; Accepted 14 March 2014; Published 24 April 2014

Academic Editor: Mark Green

Copyright (C) 2014 Angelo C. Loula et al. This is an open access article distributed under the Creative Commons Attribution License, which permits unrestricted use, distribution, and reproduction in any medium, provided the original work is properly cited.

\begin{abstract}
Ecology plays a central role in biology and deserves special attention in scientific education. Nonetheless, the teaching and learning of ecology face a number of difficulties. In order to tackle these difficulties, electronic games have recently been used to mediate ecology learning. This paper presents an electronic game that fulfills these gaps in order to make the students' work with ecological concepts more concrete, active, and systematic. The paper presents the computational model of the ecological system included in the game, based on a real ecological case, a sand dune ecosystem located in the semiarid Caatinga biome, namely, the sand dunes of the middle São Francisco River, in the state of Bahia, Brazil. It includes various ecological relationships between endemic lizards and the physical environment, preys, predators, cospecifics, and plants. The engine of the game simulates the physical conditions of the ecosystem (dune topography and climate conditions with their circadian and circannual cycles), its biota (plant species and animal species), and ecological relationships (predator-prey encounters, cospecific relationships). We also present results from one classroom study of a teaching sequence structured around Calangos, which showed positive outcomes regarding high school students' understanding of thermal regulation in ectothermic animals.
\end{abstract}

\section{Introduction}

Ecology deserves special attention in biological education because its object of study, namely, the spatial and temporal patterns of distribution and abundance of organisms, as well as their causes and consequences $[1,2]$ plays a central role in biology. Moreover, ecological knowledge gains additional importance in the current context of environmental crisis.

Despite its relevance, ecology teaching and learning face a number of difficulties. Key ecological concepts, such as ecological succession, food chains, and cycling of matter, are widely recognized as difficult to learn $[1,3,4]$. Accordingly, there is evidence that the students' knowledge on various aspects of ecology is insufficient [5].

To overcome these difficulties, electronic games have recently been used to support ecology learning, but the available ones usually lack educational goals, are not related to real situations, and do not incorporate tools specifically designed to enhance scientific abilities. The game presented here fulfills these gaps as a resource aimed at promoting learning about ecology by making ecological concepts more concrete to the students and, also, engaging them with conceptual learning in ecology in a more active manner. The game, called Calangos (a popular name for lizards in Northeast Brazil) is based on 
a real ecological case situated in the dunes of the middle São Francisco River, in the state of Bahia, Brazil, investigated by Brazilian researchers (e.g. $[6,7]$ ). The game (freely available at http://calangos.sourceforge.net/) is intended to provide the students with an environment that allows an adequate understanding of ecological processes. The objective of this paper is to present the model of the simulated ecological system, based on the real ecological case, included in the game and present results from one classroom study of a teaching sequence structured around Calangos. Particularly, the paper addresses the modeled dune environment and the ecological processes involving three lizard species that inhabit this environment.

The computational models developed include graphical models for reproducing the visual aspect of real elements of the sand dunes as game elements, mathematical models to define functions for game variables, and behavior models to describe actions and activities of nonplayable characters based on the behavior of real animals. All of these computational models operate during game play to generate a complex simulation of elements and relationships. Such simulation engine underlying the game corresponds to a flexible set of game rules and provides multiple possible trajectories for an open game play to achieve the proposed goal, a feature that differentiates serious games from mere edutainment games [8]. Serious games combine the analytical and questioning nature of scientific endeavors with the intuitive freedom and rewards of imaginative and artistic acts. In brief, serious games offer a way of exploring serious intellectual and social problems $[9,10]$.

The paper is organized as follows. The following section presents related work on educational games about ecology. Next, it described the real ecological case in which the game and its ecological model were based. Finally, the Calangos game is described, focusing on the ecological model developed, leading to the final remarks.

\section{Related Work}

The use of games to support educational activities has been studied for a long time [11]. In the case of electronic games, however, it was only recently that teachers started to use them in schools as a tool to help the teaching and learning process. Among the electronic games available to use in educational settings, a number of them are biology/ecology-inspired games that might, at least potentially, help ecology teaching and learning. This section discusses the main features of some of these games.

CellCraft (http://www.carolina.com/category/teacher+ resources/interactive+science+games+and+simulations/cellcraft.do) is a simple online game that takes students inside a cell where they can learn about how a cell works and which challenges it faces to survive in a hostile environment. The game encourages students to balance resources and grow a robust cell to fight off coldness, starvation, and viruses. It follows a linear path: the students are guided to go through fixed steps and perform specific tasks to move to the next step. The strategy is easy to program and control. This approach guarantees that the students have access to all the information they need to learn a specific topic. Nevertheless, this kind of guided path eliminates the freedom of choice that a real game should provide to the player, forcing the students to follow a standard pattern for acquiring knowledge.

Web Earth Online (http://www.webearthonline.com/) is a multiplayer web-based $2 \mathrm{D}$ game where each player can choose to play as a mammal, reptile, or bird. The game simulates a very detailed ecosystem, but it is not clear if it is based on real data. Variables like temperature, weather, rainfall pattern, and direction of air flow are used to control the simulation process. There are many kinds of interaction in the game, such as those between the player and the agents (e.g., predators, preys) and between the player and elements of the ecosystem (e.g., trees, rivers). As a strategy game, the choice of which kind of interaction the player will use is the main challenge of the game. So, for different problems, the player may choose different strategies, and different players may choose different strategies to achieve the same solution. This could be used as a learning tool, but the game did not take advantage of this feature in this way. In fact, there is no explicit educational goal to achieve. The player could play forever or, at least, until it reaches the point where there is no other player to interact with (something common in multiplayer games). Another fact that corroborates the lack of interest about the learning process is the time needed to develop the character. The player must play the game for days to make his/her character grow and evolve. This long period of play does not help the player to perceive the relations between his/her strategy and the ecological concepts involved. It is difficult to evaluate if the model used for the simulations is trustworthy or precise, because there is no indication that the simulation is based on a real ecosystem.

Spore (http://www.spore.com/) is a multigenre singleplayer God game that allows the player to develop a virtual species. The species starts as a microscopic organism and can evolve into a complex animal. Once the player reaches this stage, he/she can start to guide groups of individuals to develop social relations. In the advanced stages, the user faces the challenge of leading the species to dominate its planet and then finally to its ascension into space, where it interacts with alien species across the galaxy. So, during the evolution of the game, the player experiences different perspectives from different evolutionary stages of a species. Although this game is motivated by many biological concepts like evolution, ecosystems, mutation, and so forth, there is no real model governing these processes. Moreover, there are features that may directly promote the development of misconceptions, such as the fact that the player can obtain new body parts by examining bone piles or skeleton parts found in the landscape, or by defeating some creatures. Thus, from an educational point of view, it is difficult for the player to build any valid correlation between how life evolves during the game and how a real life form could evolve on earth or any other planet. Despite its success as an entertainment game, Spore seems to bring limited educational contributions.

By analyzing the games from a historical point of view, it is possible to see a change between games developed in the 1990's and games developed in the 2000's. Older games, like 
SimAnt (http://www.mobygames.com/game/simant-the-electronic-ant-colony), SimEarth (http://www.mobygames.com/ game/simearth-the-living-planet), Lion (http://www.mobygames.com/game/lion), Empire of Ants (http://www.mobygames.com/game/empire-of-the-ants), and SimPark (http:// www.mobygames.com/game/simpark), are simulation-based games that try to model, in a precise way, the relations between its elements and players. Some of them (e.g., Lion and SimEarth) have an explicit concern with educational issues. Others (e.g., SimAnt and SimPark) do not have this kind of feature but are based on biological information, which can provide the player with important feedback about what is going on in the environment. However, many newer games are usually based on web technology and poorly developed. They usually borrow strategies from traditional games, like quiz, puzzles, and memory games, changing only the theme, inserting biological or ecological content, or simply using pictures of animals or plants.

In this context, Calangos was developed with a major concern to reproduce a real environment, ruled by a model that is highly precise to give the player a feeling as close as possible to the lizard in its own habitat. At the same time, the game is expected to be able to reinforce the playful atmosphere of a good game, improving the interest of the player to discover which strategy can leave his/her character to achieve the game's goal: grow and reproduce. Finally, the game allows the player to access dispersion graphs that relate variables that describe the past performance of the lizard, allowing him/her to analyze the results of the strategies that he/she adopted in the past, so that he/she can adjust future strategies. Calangos explicitly incorporates tools specifically designed to enhance a key scientific ability, namely, that of interpreting graphs. To the extent of our knowledge, Calangos is the only educational game focused on biology/ecology that has a climate model based on real data and linked to models of the ecological relations between individual organisms and the environment, also based on real data, which, moreover, includes tools for the development of scientific abilities.

\section{The Real Ecological Case}

The ecological case modeled in Calangos is situated in the sand dunes of the middle São Francisco River (Figure 1), in the state of Bahia, Brazil. This ecosystem hosts an endemic and diversified flora and fauna and has been studied by Brazilian researchers for some decades now $[6,7]$. Thus, the game not only brings a Brazilian ecosystem to the students' attention, but also the contributions of the Brazilian scientific community to the understanding of this ecosystem.

To succeed in the game, the student must develop an efficient strategy for the day-to-day activity of a lizard (choosing between individuals from three different endemic species, Tropidurus psammonastes, Cnemidophorus sp. nov., and Eurolophosaurus divaricatus). The lizard must be able to choose microhabitats that provide suitable conditions of temperature and humidity and, thus, be capable of behaviorally regulating its temperature. It should also be able to avoid predators and find food to survive and grow, and, after

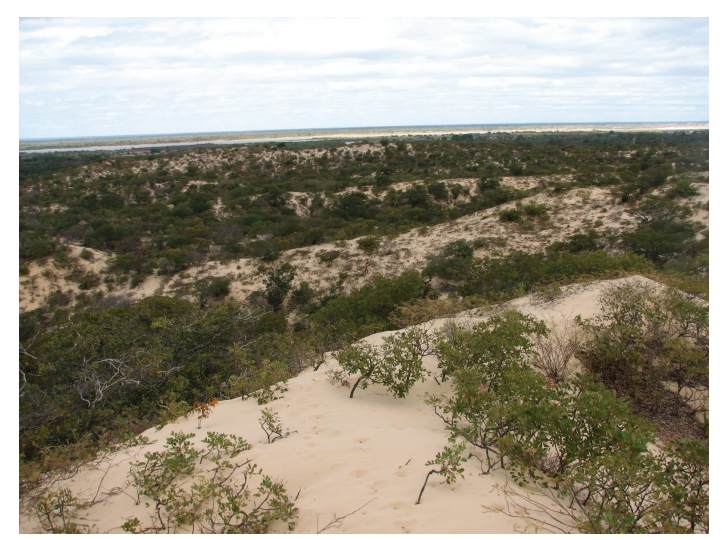

Figure 1: Picture from the sand dunes of the middle São Francisco River.

reaching adulthood, to find a sexual partner and reproduce, after fighting other males, if necessary.

The game simulates the dune environment by taking into account its real features, most of which have been specifically investigated on site. The dunes present a periodic topography, with summits, slopes, and valleys. The topography is associated with changes in the plant communities, as different plant species show different affinities for those positions. The topography, in turn, influences the distribution of resources (thermal environment, food) that are used by the animals (arthropods and vertebrates). Different plant species present different abundances in the dunes and provide different resources to the animals, including food. Animal species exhibit specific patterns of aggregation and use the available resources differently. Some are preys and predators of other animal species, and those eaten by the lizards have species-specific nutritional properties. Other species do not have trophic relationships with the lizards but may influence the resources available to them, as well as other kinds of interactions of the lizards with their environment. This is the case, for instance, of a local rodent (Trinomys yonenagae) that digs galleries in the sand that can be used as refuges by the lizards.

Daily changes in the position of the sun lead to changes in the temperature of the air and sand and in the air humidity. Seasonal changes in the climate influences the day temperature and humidity, as well as the primary productivity of plants and, therefore, the availability of food resources to animals.

The relevance of building the game inspired in this real case is twofold: (a) it allows the development of a quite realistic and nature-inspired model, given the availability of field information; and (b) it brings to the focus a relevant Brazilian ecosystem from the Caatinga Biome, which is probably one of the poorest known by most of the students in Brazil. Moreover, if the game is used by international students, this is quite an interesting example of a semiarid, savannah-like ecosystem with several endemic species, which is even more poorly known by foreign students. 


\section{The Computer Game Calangos}

Calangos is a simulation and action game with $3 \mathrm{D}$ visualization in the first and third person. In the currently available game level, the player controls a lizard from one of the three medium-sized endemic species of the sand dunes ecosystem (Tropidurus psammonastes, Cnemidophorus sp. nov., and Eurolophosaurus divaricatus).

It is an electronic educational game that works as a tool to support ecology teaching and learning (and also evolution in Level 4) at the secondary school level. Therefore, it is not a tool for direct exposure of contents to be learned by the student player. Rather, learning is to take place as a consequence of the player's experience in trying to deal with problem situations. While trying to be successful in facing the challenges of the simulated environment, the player has to develop a strategy to control its character and must take into account the game dynamics and rules, and, consequently, the simulated ecological processes. To develop this strategy, the student player has to access dispersion graphs showing relations between variables chosen by him/her from a menu of variables, evaluate what has happened in his/her previous strategy, and modify it aiming at improving the outcomes.

Four game levels are planned for Calangos. At the first level, the student player chooses among the three species of lizards mentioned above and acts as the main character, with the objective of successfully surviving, developing, and reproducing. Level two adds a lizard editor, in which the player can select different morphological, physiological, and behavioral characteristics to build a new lizard to play, with the same objectives of Level 1. The characteristics included in the lizard editor and their variants are also based on biological studies about real lizards. In Level 3, the player goes from a single individual to a population of lizards still in ecological time, with the objective of establishing a dynamical equilibrium for this population. Level 4 is the last level, which changes from the ecological time to the evolutionary time, with the player not only facing population challenges but also having to deal with the evolution of the lizards through many generations. The first level is already developed and Level 2 is currently being implemented; the two last levels are being designed and prototyped. In this paper, the goal is to describe the artificial ecological system modeled on the grounds of the real ecological case described before. This simulated ecology was developed for the first level of the game but also provides a basis for the subsequent levels, being adjusted and expanded for specific requirements. At this first level, the player begins as a lizard early in its life, situated in the dunes terrain, in which there are relevant elements from the ecosystem of the São Francisco River dunes that can be involved in ecological relations with the player-controlled lizard. As a tool to support ecology teaching and learning, the game demands that the student make use of concepts related to different ecological relationships in order to overcome the challenges faced by the lizard to survive, develop, and reproduce successfully. The next sections describe the ecological modeling of the game.
4.1. Modeling Ecology. As the player controls a lizard, the relevant ecological relationships modeled for the game were prey-lizard, predator-lizard, vegetation-lizard, lizard-lizard, and lizard-physical environment (Figure 2). Among the elements involved in ecological relationships, there are various species of plants, typical preys of lizards, various species of lizard predators, and also animals not involved in the food chains in which the lizards are engaged. Other cospecific lizards are also present in the environment, engaging in ecological relationships (e.g., competition for territory, preys, and breeding). Besides, there are abiotic elements that are part of the ecosystem, such as the climate and terrain.

Each element and each relationship were initially described by the biologists that are part of the project team by means of texts and pictures based on the published literature and accumulated knowledge $[6,7]$. The terrain, animals, and vegetation were visually modeled in three dimensions, so as to reproduce their actual visual aspect. More importantly, computational models were proposed to describe all the relevant elements and relations and establish the game simulation dynamics.

The simulation models underlying the game define an open-ended environment with multiple outcomes and game experiences and, thus, give rise to a game with a complex and flexible set of rules. In the game, simulation represents consequences to causes in an open manner, without using fixed game rules that heavily constrain player actions [3]. The player is free to move the lizard around the environment, establishing ecological relationships with any of the elements modeled. Each player experiences a different game trajectory every time the game is played. The game strategy is the behavior defined by the player when controlling the lizard at every instant of game play, carrying out the challenge of conducting the lizard to survive, develop, and reproduce.

Game simulation dynamics can be evaluated by the player through dispersion graphs made available within the game, which can show relations between variables chosen by the player. The player can make use of such graphs for decision making, by correlating the different simulation variables along time. The better the player understands the constraints and rules underlying simulation, the better he/she understands the relevant ecological relations and the more successful tends to be his/her game strategy.

It is important to note that the developed computational models had particular requirements, as they should be part of a computer game. The proposed models had to be executed in real time in a $3 \mathrm{D}$ rendering game engine and, thus, the algorithms involved could not be computationally expensive. Moreover, the goal was not to build predictive, or even fully descriptive, models of the real case. Instead, the proposed models had to describe the real case only partially, in what was necessary for the game requirements, while keeping enough plausibility and adequacy to be used as a learning tool for ecological relationships, providing valid learning experiences for the players. To put it differently, it was not the aim to accurately represent all variables from the real case, but, instead, to meet the requirement that the players' perception of the elements and their relationships should 


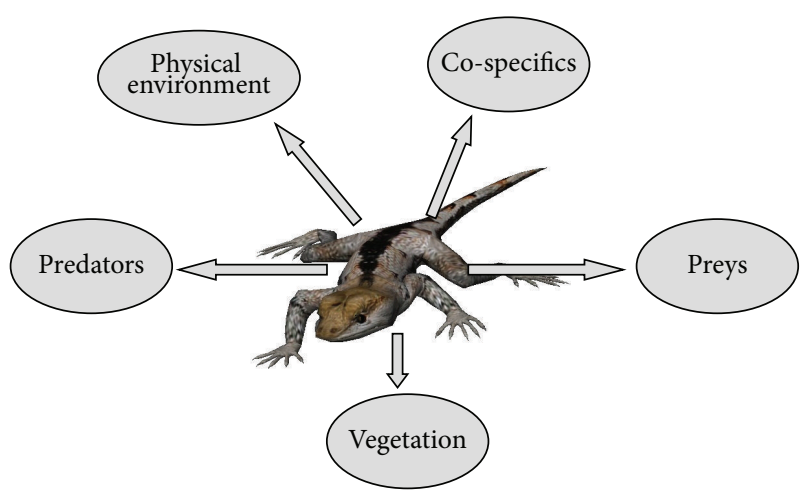

FIGURE 2: Ecological relationships modeled in the game.

be realistic enough for him/her, providing an immersive experience with fidelity to the reality representation. Despite this, it was not arbitrary implementation of the real case, but an approximation of the dynamical ecological model of the real case, considering the demands imposed by the fact that it is a game.

4.1.1. Physical Environment. The terrain and the climate were selected as physical elements to be modeled, since they are very important for the game dynamics. The artificial terrain corresponded to dunes with height and length in accordance with the sand dunes of the middle São Francisco River in the Ibiraba village (Municipality of Barra, Bahia, Brazil). Terrain limits were the river itself, a village and fences, also following information from the real region.

To model climate, the relevant variables were temperature, air humidity, and rainfall. More specifically, several variables composed the temperature: air temperature, soil temperature, and temperature in burrows made by the endemic rodent Trinomys yonenagae, which are also used by the lizards.

These climate variables affect, directly or indirectly, internal variables of the lizard. They had to model climate dynamics and, therefore, had to vary temporally along the days and months, following seasonal changes. Besides, these variables should also vary spatially, establishing microclimates corresponding to shadows from the vegetation and rodent burrows.

To establish a time flow, a virtual clock was created, parameterized by the computer real clock. Since it is a game and human interaction with the simulation is involved, time flow could not be too slow or too fast, since this could compromise playability. The default time rate is 1 virtual day every 3 minutes and 1 virtual month every 3 days, but the time rate can be configured by the player. This way the student player can experience the day-night cycle and seasons within a single class time. Moreover, a day and night cycle is also visually simulated by varying light conditions in the game and also sun and moon movements in the sky.

The spatial climate variations correspond to microclimates with more amenable or stable climate conditions. These shelters are shadows produced by solar irradiation blockage by the vegetation and also the gallery systems dug by $T$. yonenagae. These microclimates are crucial for ectothermic animals, such as the lizards.

Physical Environment: Temperature and Humidity. The first variable modeled was the air temperature and its temporal variation. Analysis of temperature variations in twenty-four hours cycles from data obtained by the Brazilian National Meteorological Institute (INMET) showed a pattern of daily variations following sunrise and sunset (Figure 3). A similar daily pattern, but in opposing phase, can be observed in the case of air humidity: the higher the temperature, the lower the humidity. In rainy days, air humidity is always high and stable.

This daily pattern of air temperature variation was empirically approximated by a time function with a curve equation for day time and a line equation for night time. This daily temperature function was parameterized by the daily highest and lowest temperatures. To determine the highest and lowest temperatures for each day in the game, historical mean values of highest and lowest temperatures for each month during various years were obtained from INMET (Table 1). The mean and standard deviation values were calculated for each month, estimating normal distribution random variables for the highest and lowest temperatures.

To establish the daily temperature variation for each new day simulated in the game, values are drawn from random variables for the highest and lowest temperatures for a given month, parameterizing the temperature function. The following function was proposed and used to model air temperature:

$$
\begin{aligned}
& T_{\text {air }}(t) \\
& \left\{\begin{array}{c}
\frac{T_{\max }-T_{\text {nextmin }}}{18} \cdot(t-6)+T_{\text {nextmin }}, \\
0 \leq t \leq 5 \\
T_{\text {min }}+\left(T_{\max }-T_{\min }\right) \cdot \sin \left((t-6) \frac{\pi}{16}\right), \\
5<t \leq 14 \\
\frac{T_{\max }+T_{\text {nextmin }}}{2}+\frac{T_{\max }-T_{\text {nextmin }}}{2} \cos \left((t-14) \frac{\pi}{14}\right), \\
14<t<22 \\
\frac{T_{\max }-T_{\text {nextmin }}}{18}(t-30)+T_{\text {nextmin }}, \\
22 \leq t \leq 24,
\end{array}\right.
\end{aligned}
$$

where $t$ is the time in hours ( $0-24$ hour), $T_{\max }$ is the maximum temperature for the current day, $T_{\min }$ is the minimum temperature for the current day, and $T_{\text {nextmin }}$ is the minimum temperature for the following day.

More important to the game than the air temperature is the soil temperature, since lizards are in close contact with the sand. To estimate the relationship between air temperature 
TABLE 1: Monthly mean temperatures measured in a meteorological station at Barra, Bahia, from 1978 to 2008. Data obtained from INMET (http://www.inmet.gov.br/).

\begin{tabular}{lcc}
\hline Month & Maximum temperature & Minimum temperature \\
\hline January & $32.6 \pm 2.6^{\circ} \mathrm{C}$ & $21.0 \pm 1.7^{\circ} \mathrm{C}$ \\
February & $32.8 \pm 2.5^{\circ} \mathrm{C}$ & $21.4 \pm 1.6^{\circ} \mathrm{C}$ \\
March & $32.3 \pm 2.4^{\circ} \mathrm{C}$ & $21.0 \pm 1.6^{\circ} \mathrm{C}$ \\
April & $32.7 \pm 2.0^{\circ} \mathrm{C}$ & $20.5 \pm 1.7^{\circ} \mathrm{C}$ \\
May & $32.5 \pm 1.9^{\circ} \mathrm{C}$ & $19.1 \pm 2.2^{\circ} \mathrm{C}$ \\
June & $31.9 \pm 1.5^{\circ} \mathrm{C}$ & $17.2 \pm 2.0^{\circ} \mathrm{C}$ \\
July & $32.1 \pm 1.3^{\circ} \mathrm{C}$ & $16.6 \pm 2.0^{\circ} \mathrm{C}$ \\
August & $33.1 \pm 1.6^{\circ} \mathrm{C}$ & $17.5 \pm 2.4^{\circ} \mathrm{C}$ \\
September & $34.5 \pm 1.7^{\circ} \mathrm{C}$ & $19.9 \pm 2.1^{\circ} \mathrm{C}$ \\
October & $35.3 \pm 2.1^{\circ} \mathrm{C}$ & $22.0 \pm 1.8^{\circ} \mathrm{C}$ \\
November & $33.8 \pm 3.0^{\circ} \mathrm{C}$ & $21.7 \pm 1.7^{\circ} \mathrm{C}$ \\
December & $32.9 \pm 2.8^{\circ} \mathrm{C}$ & $21.3 \pm 1.5^{\circ} \mathrm{C}$ \\
\hline
\end{tabular}

and soil temperature, we relied on measurements made by biologists of the project team. It was verified that soil temperature is higher than air temperature, showing an approximately quadratic relation to the latter and, also, that there is a temporal latency between them, probably due to thermal inertia. Soil temperature was modeled as a quadratic function of the air temperature with a delay of one hour and higher amplitude. The following function was used to model soil temperature:

$$
T_{\text {air }}(t)-0.0425 \cdot\left(T_{\text {air }}(t)\right)^{2}+3.9 \text {, }
$$

where the constants were empirically determined to approximately fit the data.

Temperature in microclimates (climate spatial variations) was also modeled after air temperature. According to the measurements made by the biologists of the project team, temperature inside burrows also had a delay compared to air temperature, but its amplitude variation was much smaller than the latter. Temperature in the shadow was modeled as being more moderate than the air temperature during sunlight hours, with a reduction of up to $5 \%$. Soil temperature in the shadow was up to $10 \%$ lower than soil temperature in sand in open sun.

In addition to temperature, air relative humidity is also an important variable. The air humidity function was modeled as a time function similar to temperature, but in opposing phase. The mean value and amplitude variation of humidity in days without rain were determined from daily temperature values, in a relation estimated by real data. For rainy days, humidity is kept saturated at $100 \%$. The following function was used to model air humidity:

$$
H(t)= \begin{cases}-3.9 \cdot T_{\mathrm{air}}(t)+158, & \text { if not raining } \\ 100, & \text { if raining, }\end{cases}
$$

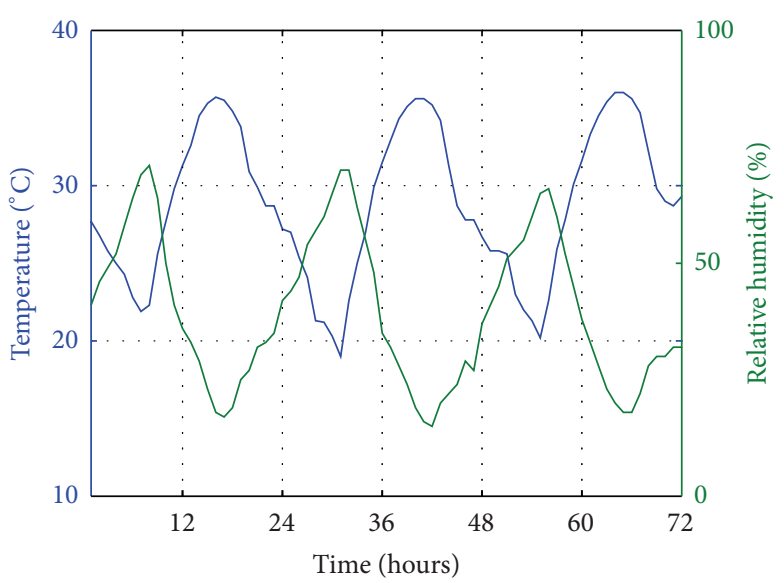

FIGURE 3: Temperature and air humidity measured in a meteorological station at Barra, Bahia, municipality in which the dunes region is located, for a period of 3 days in September 2008. Data obtained from INMET (http://www.inmet.gov.br).

where the constants were empirically determined to approximately fit the data.

To determine when rain would occur, it was first assumed that if rain occurred, it would last for the whole day. To determine in which days in a month it would rain, historical rain data from INMET were analyzed, establishing mean values and standard deviations for each month and, thus, a random variable with normal distribution for the monthly amount of precipitated rain. Finally, to determine if it would rain in a certain day in the game, it was assumed that the month with the highest rain level was a month in which it rained every day. During simulation, after drawing a value for rain level in a given month from the respective random variable, this value is divided by the highest rain level to determine an estimated number of rainy days. The estimated number of rainy days divided by the number of days in a month gives a probability of rain in each day in that month.

Figure 4 illustrates the simulated air temperature and humidity in the game. It shows a roughly similar pattern to the real data exhibited in Figure 3. Figure 5 shows the different temperature variables modeled in the game.

4.1.2. Fauna. The ecological relationships of lizards, predators, and preys and also the relationships between the lizard controlled by the player and its cospecifics are elements of the fauna that need to be modeled. Preys and predators present in the game were defined by the biologists in the team, in accordance with the actual animals found in the real ecological case and in studies on the diet of the lizards. These animals were graphically modeled, reproducing their visual aspect and enforcing immersion, and behaviorally modeled, representing actions and activities that are relevant to the ecological relationships.

Predators include the terrestrial, diurnal bird seriema (Cariama cristata), a nocturnal owl, the diurnal hawk southern Caracara (Caracara plancus), the nocturnal snake jararaca (Bothrops neuwiedi), a diurnal Colubridae snake, the 


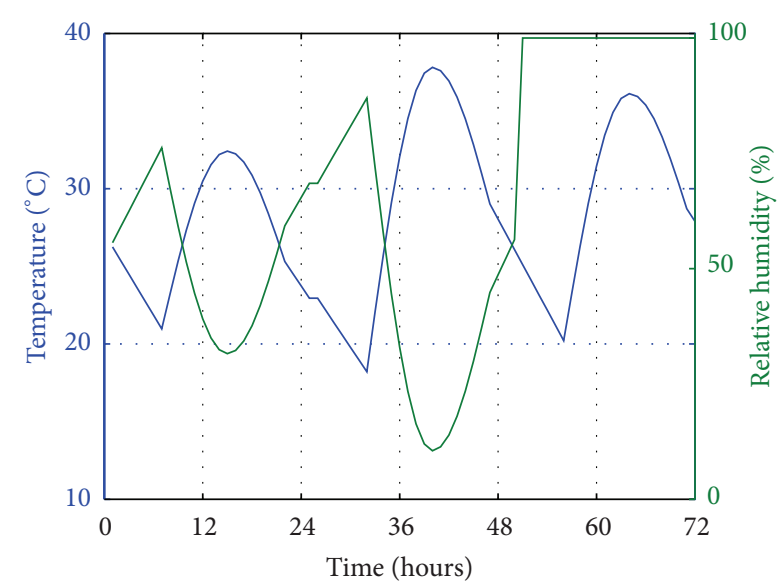

FIGURE 4: Simulated air temperature and humidity for three days, with rain in the third day, for the month of September.

hoary fox (Lycalopex vetulus), the wildcat, and the large-sized lizard tegu (Tupinambis merianae). All of them have a visual three-dimensional model and exhibit a simple behavior of wandering around the terrain. If a predator approaches a lizard (either the player's or others), it starts chasing the lizard until it gets close enough to attack it (Figure 6). The lizard can only hide from predators if it enters into burrows or if it is close to plants. Every time the player's lizard is attacked, it loses energy. A full predation is not possible upon a single predator attack to preserve game playability.

Ants, termites, maggots, grasshoppers, beetles, and spiders are the preys present in the game, all with a threedimensional visual representation. We defined three types of behavior for the preys in order to approximate general differences found in the actual behavior of these animals and to add complexity to the building of survival strategies by the students. Beetles, grasshoppers, and maggots keep wandering in the environment, at different velocities. Spiders stay around a plant, moving occasionally. Ants and termites wander in groups around plants. Each prey type appears in different numbers in the environment, depending on whether it is night time or day time.

To eat the preys, the lizard has to get close to them (Figure 7). Each prey type corresponds to a different nutrition level (energy and hydration provided to the lizard) in order to allow the player to experience the dietary diversity observed in the real lizards. These nutrition levels were set based on current biological information in a way that adds plausibility to the model.

There are also interactions between the player's lizard and other cospecific lizards. Male and female cospecific lizards exhibit different behaviors that were inspired by current scientific knowledge on lizard patterns of action during social encounters.

The player always controls a male lizard and every time it gets closer to another male there can be a dispute for territory or for female choice (Figure 8). The dispute starts with headbobbing, when a lizard nods to indicate that it is ready to fight, trying to make the other individual flee. In the game, a lizard may flee from the player's lizard with a probability proportional to their size difference but only if the player's lizard executes bobbing. Without bobbing, the other male will always start a fight with the player's character. The fight involves getting close to the other lizard and biting it, taking energy away, proportionally to the difference in size. If the other male reaches a low energy level, it flees and gives up the dispute.

The female lizard interacts with the male lizards only for mating and reproducing. The final objective of the lizard is to live and reproduce as much as possible. The female will only reproduce with a male lizard if it is the only one around her. If two males are near a female, one of them has to flee before the female agrees to mate. As explained above, this may involve fights between the lizards. Once reproduction occurs, the female cannot reproduce again for a whole day. Every time the player's lizard reproduces, its score (which is an egg count) is increased by one. Since the player's lizard begins as an infant, only after twelve months it reaches sexual maturity and is able to reproduce. Before that, the player has to develop and survive.

4.1.3. Flora. The flora present in the game is composed of fifteen different species of plants, all graphically modeled, also to enforce immersion. These plants have a characteristic distribution in the real sand dunes: some of them are found in the summit of the dunes, some in the slope, and others only in the valley. The same distribution is also present in the game simulated environment.

In the real dunes, plants are also part of the food chain of the lizards: some of them produce flowers and some produce both flowers and fruits which can be eaten by the lizards, therefore contributing to the lizard's energy and hydration (Figure 9). Moreover, the production of flowers and fruits by the plants follows seasonal variations. All these aspects were simulated by the game and, therefore, the player can notice the influence of seasonal changes in the lizard's diet.

Besides being a food source, plants are also sources of amenable microclimates. Shadows are placed only around plants (Figure 9), which are also hiding spots for the lizards to avoid predators.

4.1.4. Player's Lizard. The player's lizard is the main character and source for the experience of ecological relationships. Therefore, it is the most complex element in the game, since every ecological interaction comprises features to be developed in this character.

There are many variables and processes related to the player's lizard that were planned to incorporate relevant biological concepts to the game (Figure 10; see Table 2 for variables). The most relevant variables are energy, hydration, and internal temperature.

Energy is a value between $0 \%$ and $100 \%$ that represents the energy stored by the lizard. Energy lowers every second due to energy expenditure, which involves basal energy expenditure necessary to keep the lizard alive and energy for movement. Basal energy expenditure can vary depending on the internal temperature: temperatures above the ideal range 


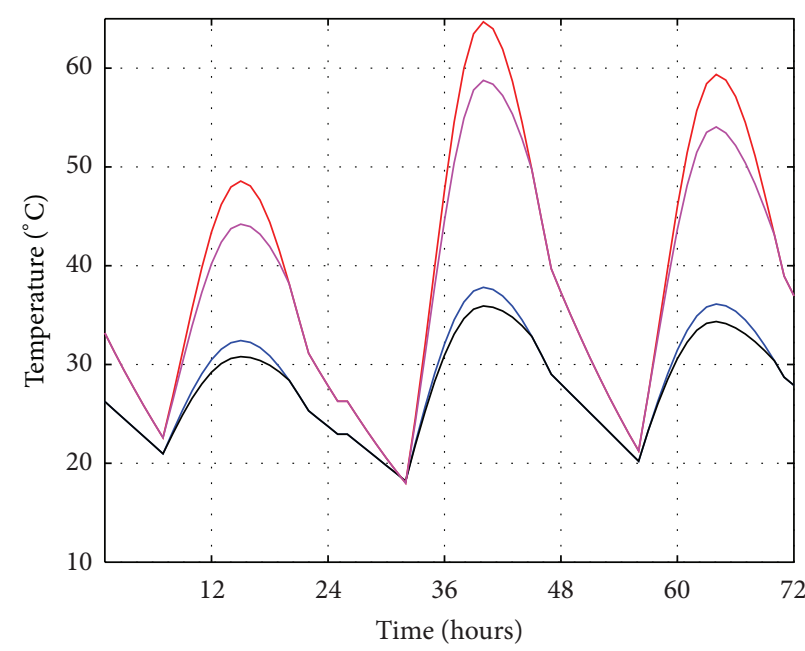

$\begin{array}{ll}\text { - Air temperature } & \text { - Air temperature in shadow } \\ \text { Soil temperature } & \text { Soil temperature in shadow }\end{array}$

(a)

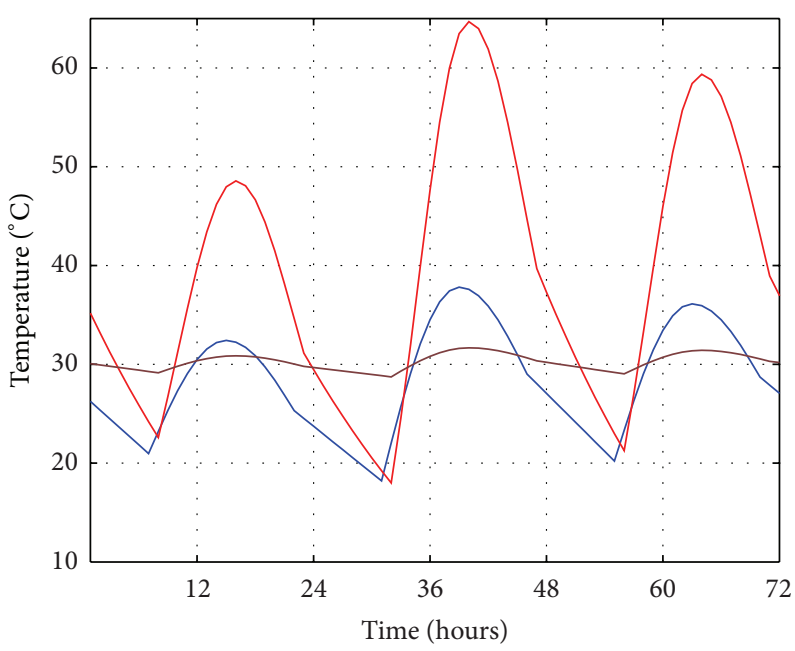

$\begin{array}{ll}\text { - Air temperature } & - \text { Burrow temperature } \\ \text { Soil temperature }\end{array}$

(b)

FIGURE 5: Simulated temperatures for three days in different conditions.

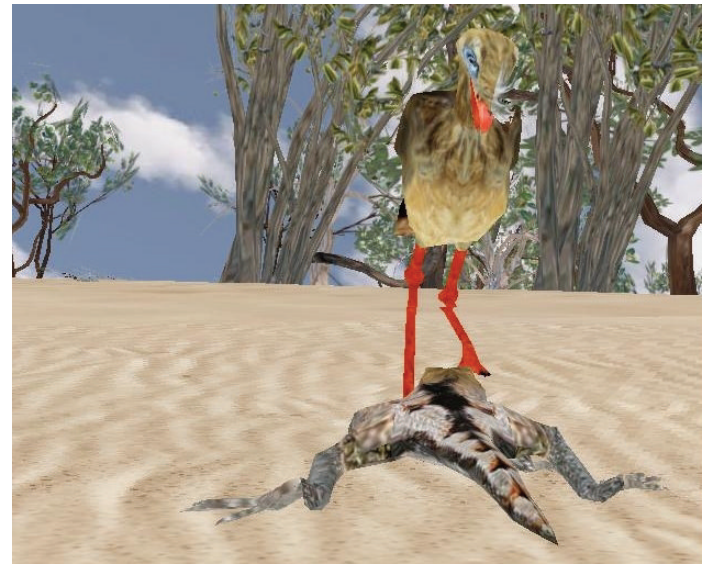

FIGURE 6: A predator (seriema) attacking the lizard.

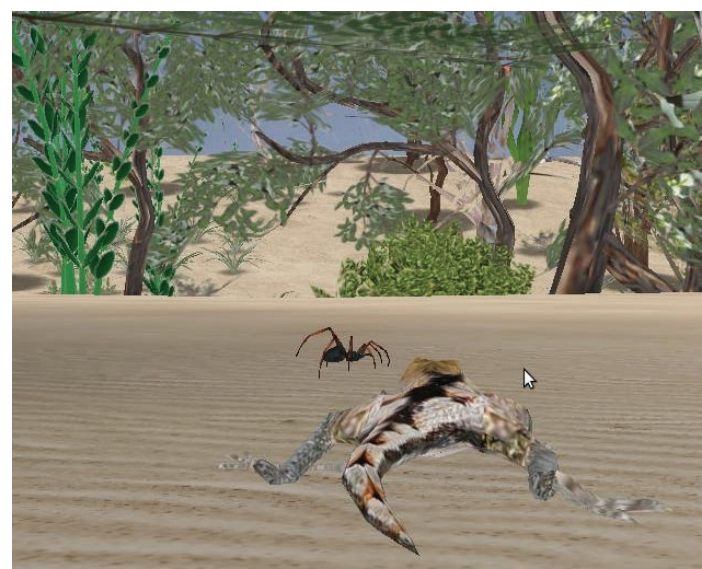

FIGURE 7: Lizard approaching a prey (spider).

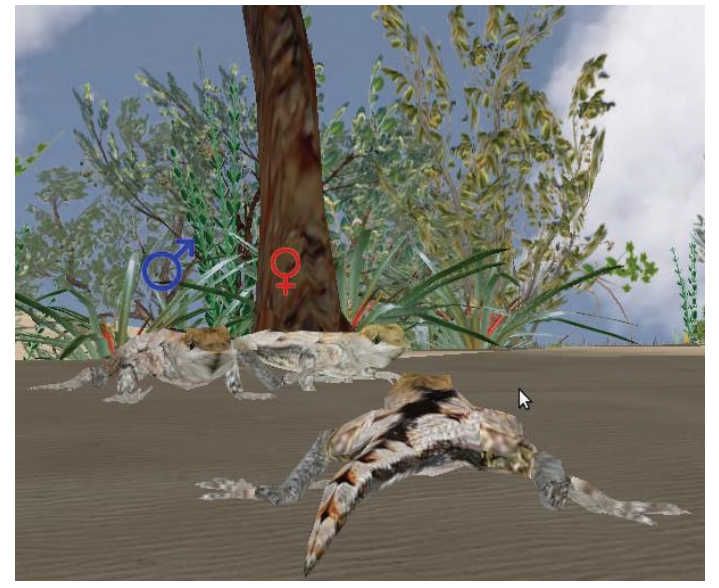

FIGURE 8: Male and female lizards close to the player's lizard.

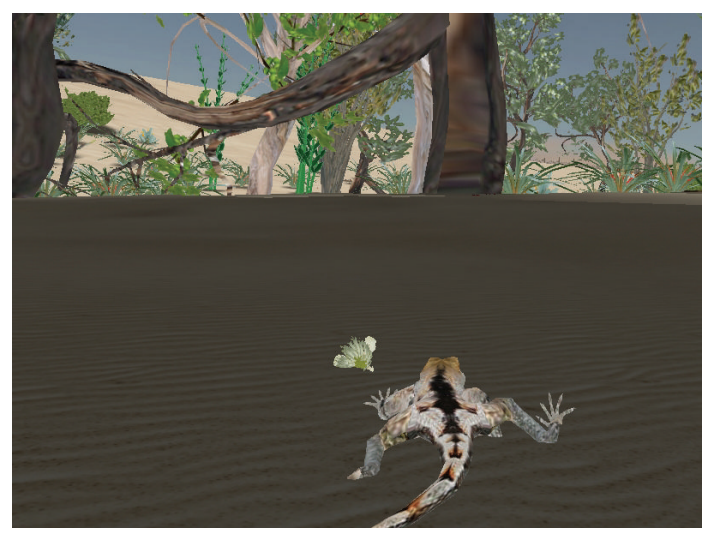

Figure 9: Lizard and plants in the dunes. Note the shadows under the plants and the white flower on the floor in front of the lizard. 
TABLE 2: Player's lizard main variables.

\begin{tabular}{lc}
\hline Variable & Range/unit \\
\hline Energy & $0 \%$ to $100 \%$ \\
Hydration & $0 \%$ to $100 \%$ \\
Internal temperature & $0^{\circ} \mathrm{C}$ to $50^{\circ} \mathrm{C}$ \\
Age & 0 to 36 months \\
Energy expenditure & $0 \%$ to $100 \%$ per time unit \\
Size & $0 \%$ to $100 \%$ \\
\hline
\end{tabular}

raise the basal energy expenditure, whilst temperatures below that lower the expenditure but make the lizard lethargic. Energy for movement depends on the lizard speed: running speed has higher energy expenditure, walking speed has a lower expenditure, and standing still has no expenditure besides the basal one. Energy rises when the lizard eats preys, flowers, or fruits, with each of them contributing to a different amount of energy and hydration.

The current energy for the player's lizard is defined according to the following equations:

$$
\begin{aligned}
& \operatorname{Energy}(t)=\operatorname{Energy}(t-1) \\
& - \text { TotalEnergyCost }(t)+\text { FoodEnergy }(t), \\
& \text { TotalEnergyCost }(t) \\
& =\text { BasalEnergyCost }(t) \cdot \text { TemperatureCost }(t) \\
& \cdot \text { MovementCost }(t),
\end{aligned}
$$$$
\text { BasalEnergyCost }(t)=\text { INITENCONS } \cdot \text { SIZEFACTOR, }
$$$$
\text { TemperatureCost }(t)
$$

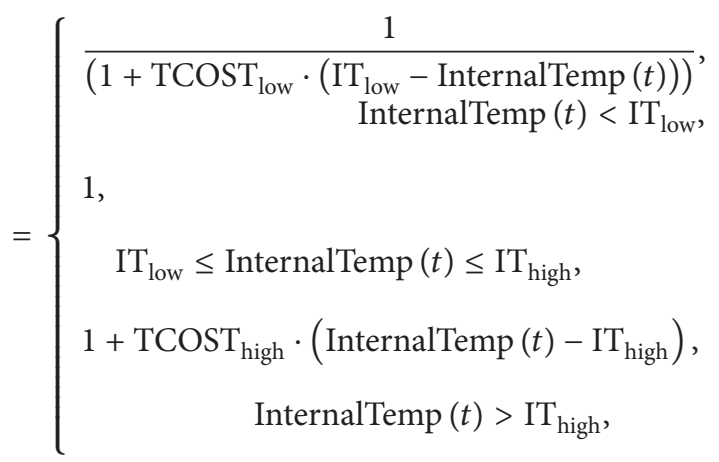$$
\text { MovementCost }(t)= \begin{cases}\text { COSTRUN, } & \text { runnning } \\ \text { COSTWALK, } & \text { walking } \\ 1, & \text { stopped, }\end{cases}
$$

where FoodEnergy is how much energy was gained by eating; INITENCONS is a constant that represents how much time it takes for all initial energy $(50 \%)$ to be consumed; SIZEFACTOR is a constant proportional to the relative size of the lizard; the bigger the lizard the higher the basal energy expenditure; TCOST is a constant that represents how much total energy expenditure is reduced (TCOST ${ }_{\text {low }}$ ) or increased $\left(\mathrm{TCOST}_{\mathrm{high}}\right.$ ) when internal temperature is below the minimum ideal temperature $\left(\mathrm{IT}_{\text {low }}\right)$ or above the maximum ideal temperature $\left(\mathrm{IT}_{\text {high }}\right)$; COSTRUN and COSTWALK are constants that represent how much the total energy expenditure is increased when the lizard is running or walking.

Hydration is also a value between $0 \%$ and $100 \%$. It rises when the lizard feeds and lowers gradually along time when air humidity is lower than a threshold of $40 \%$.

The internal temperature is a crucial variable for the lizard, since it is an ectothermic animal that cannot rely on internal metabolism to regulate temperature and, thus, must regulate temperature behaviorally, moving to cooler or warmer places when it needs to diminish or increase its temperature, respectively. The player should try to maintain the lizard's temperature at an ideal range, close to $38^{\circ} \mathrm{C}$, a value also inspired by the real species. If the lizards' temperature is out of the ideal range, the basal energy expenditure is altered as explained before. When the internal temperature rises above a maximum temperature value, the lizard dies. If the internal temperature is lower than the ideal range, the lizard does not die but suffers a speed reduction and starts having a growing chance of failing to execute actions such as eating (biting food) or fighting other male lizards.

Internal temperature varies according to the soil temperature, but not instantly, as the lizard has a certain thermal inertia to thermal equilibrium

$$
\begin{gathered}
\text { InternalTemp }(t)=\text { InternalTemp }(t-1)+\text { TEMPEQ } \\
\cdot(\text { SoilTemp }(t)-\text { InternalTemp }(t-1)),
\end{gathered}
$$

where $t$ is time in hours, InterTemp is the lizard's internal temperature, SoilTemp is the soil temperature, and TEMPEQ is a constant defining how fast internal temperature converges to soil temperature. At the beginning of the game, the thermal inertia is low, with a high value to TEMPEQ, but TEMPEQ lowers as the lizard's size increases.

The lizard's size increases according to its age. At the end of every month, the mean energy value determines how much the lizard's size increases. If the monthly mean energy was $100 \%$, then the lizard grows at a maximum rate at the end of that month. If the mean energy value is lower than $100 \%$, then the lizard's size increases at a proportionally lower rate. As a lizard grows, its walking and running speed increases, but so does the movement and basal energy expenditures. Therefore, a larger lizard can chase preys faster and also flee faster from predators, but it has to eat more to keep its energy level.

\section{Simulating the Ecological Relationships}

The computational models described above amount to a representation of the ecological case upon which the game is based. During game play, all these models are effectively operated, providing a simulated environment where the lizard controlled by the player is situated. To increase awareness and understanding of the different ecological processes and relationships, information about the environment and the lizard, besides being simulated, needs to be observed by the player. 


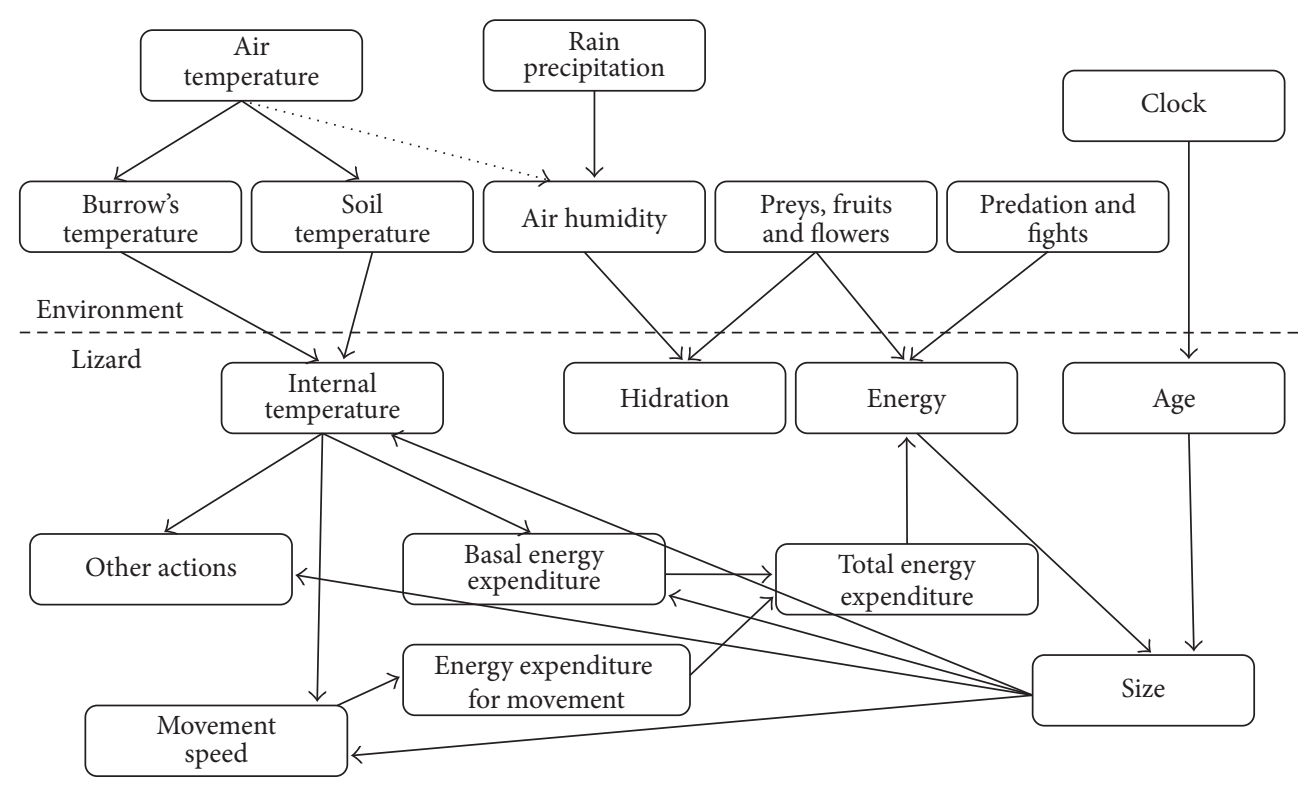

FIGURE 10: Diagram of the most relevant variables for the player's lizard and for the environment, showing also the relations among them.

Therefore, the user interface has to visually present relevant aspects of the various elements. The visualization of elements such as the terrain, fauna, and flora is straightforward, since such elements were graphically modeled and positioned, so the user sees them from a first-person or third-person perspective. Variables, such as soil temperature, internal temperature, and energy, however, have to be exhibited by means of other graphical user interface components.

While playing the game, the student player has instant information regarding the lizard and the environment, such as time, energy level, hydration, internal temperature, air temperature, air humidity, age, sexual maturity, and number of successful reproductions. Moreover, the player can also have access to time graphs for the past 24 hours of many variables, including internal temperature, hydration, air temperature, soil temperature, humidity, energy, and energy expenditure, by means of an interface that allows him/her to select which variables he/she want to plot in two-dimensional dispersion graphs (Figure 11).

To illustrate results obtained by the simulation models during game play, Figure 12 shows a sample of 24-hour graphs of some variables. This sample simulation was done playing the game for one simulated day that lasted 3 minutes in real time. The 24-hour period started at sunrise. The lizard went out in the sun, looking for preys and eating them. As night started, the lizard was attacked by a predator.

As can be noted by the graphs, climate variables are not continuously updated during simulation, but only hourly. This was done because climate variables do not change rapidly and also because it was a way of reducing computational cost.

At sunrise, air and soil temperatures were low and thus the player's lizard had its internal temperature decreased (Figure 12(a)). As the environmental temperature raised and the lizard was under the sun, the lizard's internal temperature stopped dropping and began to increase. The time where the highest internal temperature was observed did not match the time showing the highest air temperature, as the lizard is more affected by the soil temperature, which has a delay in relation to the air temperature. Besides, the lizards' internal temperature also had a short delay compared to the soil temperature, due to thermal inertia.

While the air temperature increased, the air humidity decreased but never reached a level below 40\% (Figure 12(b)). Therefore, the lizard's hydration never decreased in this 24hour period. But it increased every time the lizard ate a prey and so did its energy value. Every increase in energy and hydration was due to the lizard's feeding.

Energy expenditure varies a lot during this simulation (Figure 12(c)). Every sudden increase with subsequent decrease in energy expenditure was due to the lizard's movements, as running increases energy consumption. Energy expenditure also varied due to changes in basal energy expenditure as the lizard's internal temperature varied. The higher the internal temperature, the higher the basal energy expenditure. At hour 18, energy level dropped considerably. This happened because the player's lizard was attacked repeatedly by a predator while standing still. Every attack promoted an energy level decrease. Afterward, the lizard fled running from predator and got near a tree to hide from it. The lizard stayed in this position as the 24-hour period ended.

Energy, temperatures, humidity,and hydration are variables that can have their instant value and time variation observed by the player inside the game. The sample play described here illustrates how the ecological dynamics inside the game can be evaluated by the player to better understand game play and therefore determine a better game strategy. 


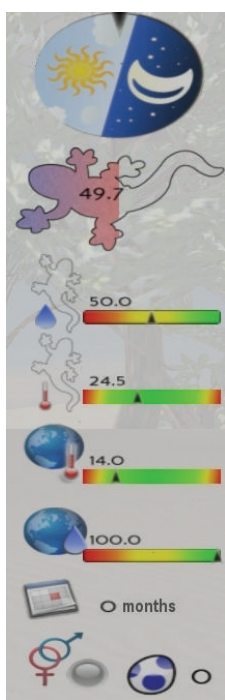

(a)

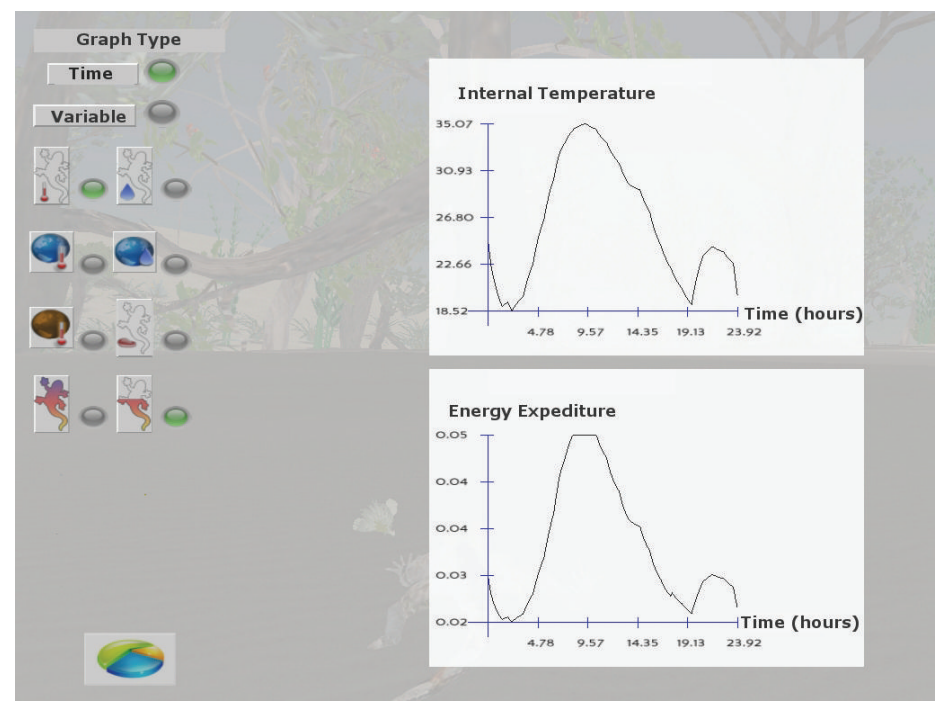

(b)

FIGURE 11: During game execution, the player has access to instant values of various simulated variables (a) and also to changes along time of these variables by means of a graph generator interface (b).

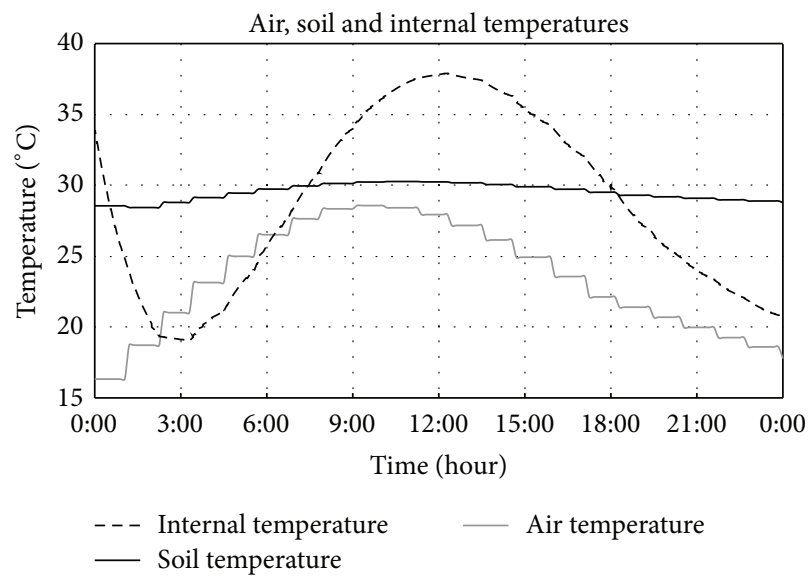

(a)

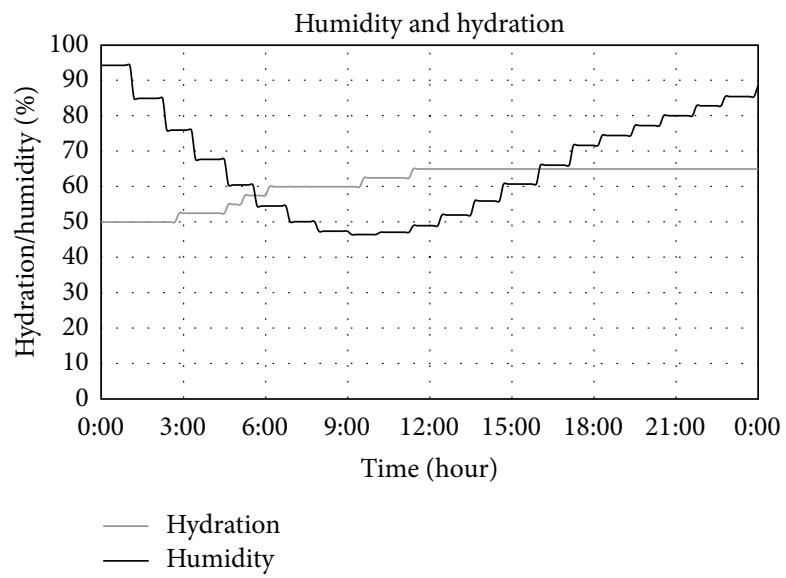

(b)

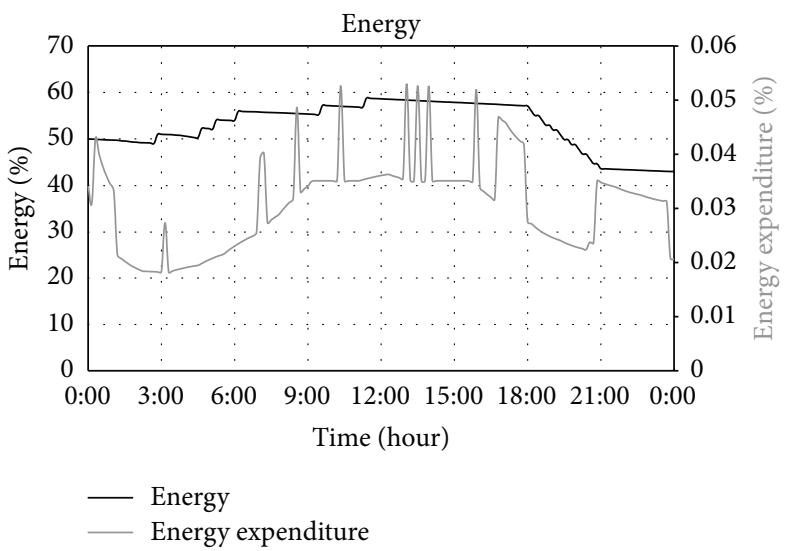

(c)

FIGURE 12: Graphs for a $24 \mathrm{~h}$ period of game simulation showing temporal variation in (a) temperatures, (b) hydration/humidity, and (c) energy. 


\section{Using Calangos in the Science Classroom}

In order to investigate the educational potential of the game Calangos, we used it in the science classroom as part of a teaching sequence for ecology teaching at the high school level, in a public school in Feira de Santana, Bahia, Brazil. Given the educational goals of the teaching, we focused on its contribution to teaching and learning about ecological niche, one of the key subject matters in ecology, which can be addressed through the game.

In many textbooks, the ecological niche is treated as an organism's "profession" in the ecological systems, in connection with Whittaker and colleagues' proposal of distinguishing between niche and habitat [12]. Nevertheless, as discussed by Sepulveda and El-Hani, this conception of niche is inadequate to build an understanding that can help teaching and learning about evolution and, for that matter, also ecology, since it does not stress the role of limiting factors and competition in either the structuring of ecological systems or the evolutionary process [13]. Other conceptions about niche are more appropriate for these educational goals, such as Hutchinson's conception of the niche as a $n$ dimensional hypervolume delimited by the environmental conditions and resources defining the requirements of a species to survive and exhibit its mode of living [14].

We developed the teaching sequence structured around Calangos. In this study, we were guided by the hypothesis that Calangos could help in promoting the construction of an understanding of this conception of ecological niche, more specifically, based on the analysis of thermal regulation as one of the challenges for lizard survival implemented in the game. The teaching sequence include six steps: (1) presentation of the game and its playing dynamics, (2) use of the game by students pairs, (3) proposal of hypotheses for the survival difficulties faced by the lizards (in the game) by means of discursive interactions between students and teacher, (4) discussion of the challenge of thermal regulation in the game, (5) orientation for the students to consider the behavior of the variables found at the side bar and the graphs made available by the game (since they typically pay scant attention to them while playing), and (6) an explicit approach of the Hutchinsonian niche by the teacher, applied to the context of thermal regulation and using students' experience with the game.

The teaching sequence was implemented in three high school first year classes in two 100-minutes sessions, involving 45 students ranging from 15 to 16 years. Both sessions were fully videotaped, comprising 10 recording hours. In the videotaped classes, we selected episodes in which discursive interactions between students and between them and the teacher allowed us to evaluate the students' behavioral engagement in the activities [15] and the meaning making process about the ecological niche in the context of thermal regulation [16]. Moreover, we applied a questionnaire in a pretest-posttest design in order to evaluate the game role in promoting conceptual learning. The questionnaire comprises three task situations evaluating students' understanding about (1) the relation between environmental temperature variation and body temperature variation in ectothermic animals, (2) the behavioral strategies used by these animals for regulating body temperature, and (3) the concept of ecological niche. For evaluating (1), a graph was presented, showing the increase of environmental temperature and the increase of the lizard internal body temperature along time, followed by one question concerning what information the students were able to extract from the graph, and another question requiring that they explain why frequent temperature variations in a semiarid environment challenged lizard survival. For (2), a picture showing lizard behavioral changes in different periods of the day was provided, and then the students were asked to explain why the lizard remained below a rock at noon, how the shown behavioral changes were related to the relation between environmental and body temperature previously analyzed, and what those behavioral changes revealed with regard to the lizard survival strategies. For (3), the questionnaire provided a scenario describing the sand dunes of the middle São Francisco River, which provided the real case for developing Calangos, and the students were prompted to write a text describing the challenges faced by the lizards to survive and reproduce in that environment. To write the text, they were asked to use the following terms: ecological niche, environmental temperature, soil temperature, lizard internal temperature, hypothermia, hyperthermia, survival, predator, and reproduction. We obtained questionnaires for 18 students in both pretest and posttest. We discuss below some results for providing a glimpse of the results obtained with Calangos use in the science classroom. Finally, to evaluate students' experience while playing Calangos, we asked them to answer the following simple question: "what did you think of the game Calangos?"

In the classroom, discursive interactions during which the biological phenomena simulated in Calangos were discussed, we could observe that the students were capable of articulating their experiences while playing the game with the challenges for the survival of an ectothermic animal. The following excerpt provides an example:

Teacher. What else happened in the game?

Students. We died.

Teacher. Why?

Student 1 . Due to high temperature.

Student 2. Due to malnutrition and low temperature.

Teacher. How do you solve this problem, death by high temperature?

Student 3. Isn't just stay in the shadow?

Student 4. But then the lizard dies from the cold.

Student 3. That's true.

Student 5. Then, he should go to the shadow and to the sun to even the body temperature. Not to even... to adjust.

Student 6. To balance the temperature.

Teacher. Kind of adjusting. Why does this happen with lizards? Why do lizards have "cold blood"? What would "cold blood" mean? 


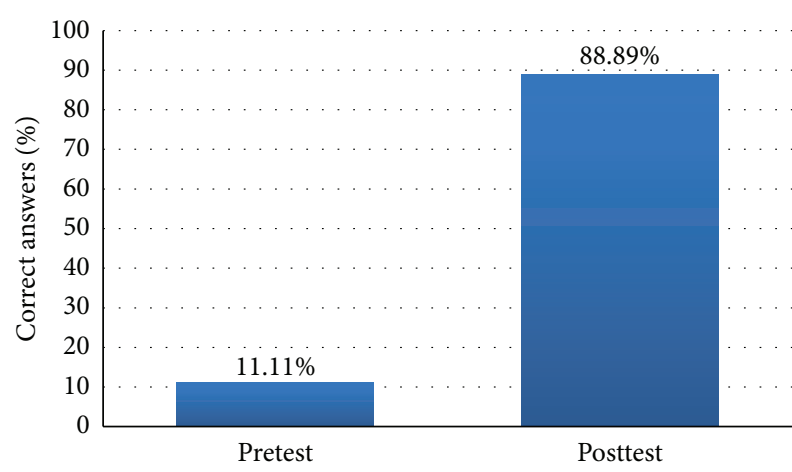

Figure 13: Percentage of correct answers to the question about the behavioral strategies used by lizards for regulating body temperature.

\section{Student 5. It depends on the sun to keep...}

Teacher. It depends on the environment to regulate internal temperature. They are ectothermic animals.

This finding agrees with the questionnaire data, in which most students (12 out of 18) showed in their answers that they understood how the body temperature of ectothermic animals varies with the environmental temperature. One student, for instance, wrote in the pretest that temperature variation common in semiarid environments are a challenge for the life of a lizard that needs to maintain a stable body temperature. In the posttest, the same student showed a deeper understanding of the phenomenon at stake, writing that the animal needs to control its internal temperature and, thus, should use behavioral strategies to regulate body temperature, exposing itself to the sun or moving to shadowed microenvironments depending on how the body temperature varies with the environmental temperature. With the experience of playing and discussing about Calangos in the classroom, this student's understanding shifted from a superficial view on lizard body temperature control to a deeper view including important aspects related to behavioral strategies for temperature regulation.

When the students were asked in the questionnaire to explain why a lizard remained below a rock at noon, their answers in the pretest did not relate the fact that lizard stayed below the rock to body temperature regulation (Figure 13). As an example, we can mention the following answer: "he is resting, because the sun is too hot and he goes below the rock to rest". In the posttest, in turn, most of them explained that behavior as a strategy used by the animal to keep its body temperature within an adequate range (Figure 13). This student's answer provides an example: "environmental temperature is too high at this time and then it protects itself in the shadow, so that its body temperature is not raised, and, thus, it avoids death."

Concerning the concept of ecological niche, the learning outcomes were much more limited. In the pretest no student used the term "ecological niche" in their texts. In the posttest, only four students used the term "ecological niche" in their texts, suggesting that most of them did not master its meaning after the intervention. This interpretation is reinforced by answers like the following: "the lizard living in this environment (sand dunes) depends on the soil temperature and the ecological niche to survive." These limited outcomes are likely to be related to the rather abstract nature of the Hutchinsonian niche, showing that it will be necessary in future applications of the teaching sequence using Calangos to expand on the its discussion in the classroom, paying also more attention to the shifting from the more concrete situations experienced by the students in the game and the more abstract reasoning involving in treating the niche as a $n$-dimensional hypervolume.

Other students' answers showed promising outcomes for this shift to a more abstract understanding of the niche, since they identified environmental factors affecting the lizard chances of survival and reproduction, which amount to an important step towards formulating the Hutchinsonian interpretation of the niche. In the pretest, 11 students mentioned some biotic and/or abiotic variable influencing the survival and reproduction chances. In the posttest, this was observed in 17 out of the 18 students. Here is an example: "there are several challenges that the lizard should face, such as escaping predators, feeding, and finding water. But the worst problem is how to keep the temperature and this demands survival strategies, such as staying in the shadow" (posttest).

Besides supporting conceptual learning, the game Calangos motivated the behavioral engagement of the students in interpreting and discussing the biological phenomena simulated in the game, as we could observe in the classroom discursive interactions. This was also shown independently in the questionnaire answers. All 18 students regarded the game as interesting, fun, and educationally important. A student, for instance, described her experience with the game as follows: "very nice and interesting, because we end up getting involved in the game. I felt as I was myself there".

\section{Conclusion}

Electronic games can be a relevant resource for ecology teaching and learning. Calangos is a game that can aid in this task by providing a simulated scenario based on a real ecological case. The simulated ecosystem developed for the game includes a variety of ecological relationships related to a lizard controlled by the student player. The computational models developed, which were discussed in this paper, define a complex network of interrelated elements. To achieve survival and reproductive success, the player must define his/her strategy, facing challenges such as that of deciding when and what to hunt and eat, while paying close attention to the behavioral regulation of the lizard's temperature. To better define a game strategy, the player must understand, however, the game mechanics and this entails that he/she must comprehend the ecological dynamics. In this way, ecological contents can be learned in an active and consistent manner.

An important asset for the development of the simulated ecosystem for the game was the presence of a multidisciplinary team of biological, science education, and computer science researchers. During the whole development process, 
software requirements were defined and reviewed to better cope with both biological plausibility and educational objectives. We already investigated the game potential for promoting ecology learning and supporting ecology teaching in the classroom, as discussed above, producing evidence for its contributions for teaching and learning about key ecological matters, such as thermal regulation through behavior in ectothermic animals. We found some limits, however, in promoting learning of more abstract concepts, such as the Hutchinsonian niche, through a teaching sequence structure around the game. The next step in the project is to assess and validate the game as a learning tool in a broader set of high school classrooms, using a new version of the teaching sequence addressing the limits observed in this previous study.

\section{Conflict of Interests}

The authors declare that there is no conflict of interests regarding the publication of this paper.

\section{Acknowledgments}

The authors would like to acknowledge Marta Vargens, Yupanqui Julho Muñoz, Emerson Silva de Oliveira, Thiago do Carmo Lima, Jairo Henrique dos Santos Calmon, Carlos Bezerra, Paulo César de Alencar Gonçalves Filho, Fladmy Alves de Souza, Jônatas dos Santos Correia, Leonardo Lima and Eduardo de Oliveira, who have participated in the research project, and also the support of FINEP, CNPq, Fapesp, Fapesb, and UEFS. CNPq granted PLBR and CNEL a research fellowship during the development of this work. They are also thankful to the students involved in the high school classroom study reported here.

\section{References}

[1] E. Sander, P. Jelemenská, and U. Kattmann, “Towards a better understanding of ecology," Journal of Biological Education, vol. 40, no. 3, pp. 119-123, 2006.

[2] S. M. Scheiner and M. R. Willig, "A general theory of ecology," Theoretical Ecology, vol. 1, no. 1, pp. 21-28, 2008.

[3] T. R. Cottrell, "Capturing difficult botanical concepts with a net of previous knowledge," The American Biology Teacher, vol. 66, no. 6, pp. 441-445, 2004.

[4] J. D. Proctor and B. M. H. Larson, "Ecology, complexity, and metaphor," BioScience, vol. 55, no. 12, pp. 1065-1068, 2005.

[5] B. H. Munson, "Ecological misconceptions," Journal of Environmental Education, vol. 25, no. 4, pp. 30-34, 1994.

[6] P. L. B. Rocha, L. P. Queiroz, and J. R. Pirani, "Plant species and habitat structure in a sand dune field in the brazilian Caatinga: a homogeneous habitat harbouring an endemic biota," Revista Brasileira de Botânica, vol. 27, no. 4, pp. 739-755, 2004.

[7] P. L. B. Rocha and M. T. Rodrigues, "Electivities and resource use by an assemblage of lizards endemic to the dunes of the São Francisco River, northeastern Brazil," Papéis Avulsos de Zoologia, vol. 45, pp. 261-284, 2005.
[8] D. Charsky, "From edutainment to serious games: a change in the use of game characteristics," Games and Culture, vol. 5, no. 2, pp. 177-198, 2010.

[9] C. C. Abt, Serious Games, University Press of America, Lanham, Md, USA, 1987.

[10] D. R. Michael and S. L. Chen, Serious Games: Games that Educate, Train, and Inform, Thomson Course Technology, Boston, Mass, USA, 2005.

[11] D. Fundenberg and D. K. Levine, The Theory of Learning in Games, MIT Press, Cambridge, Mass, USA, 1998.

[12] J. H. Whittaker, S. A. Levin, and R. B. Root, "Niche, habitat and ecotope," American Naturalist, vol. 107, no. 955, pp. 321-338, 1973.

[13] C. A. S. Sepulveda and C. N. El-Hani, "Adaptacionismo versus exaptacionismo: o que este debate tem a dizer ao ensino de evolução?" Ciência \& Ambiente, vol. 36, pp. 93-124, 2008.

[14] G. E. Hutchinson, "Concluding remarks," Cold Spring Harbor Symposium on Quantitative Biology, vol. 22, pp. 415-427, 1957.

[15] J. A. Fredricks, P. C. Blumenfeld, and A. H. Paris, "School engagement: potential of the concept, state of the evidence," Review of Educational Research, vol. 74, no. 1, pp. 59-109, 2004.

[16] E. F. Mortimer and P. H. Scott, Meaning Making in Secondary Science Classrooms, Open University Press, Maidenhead, UK, 2003. 

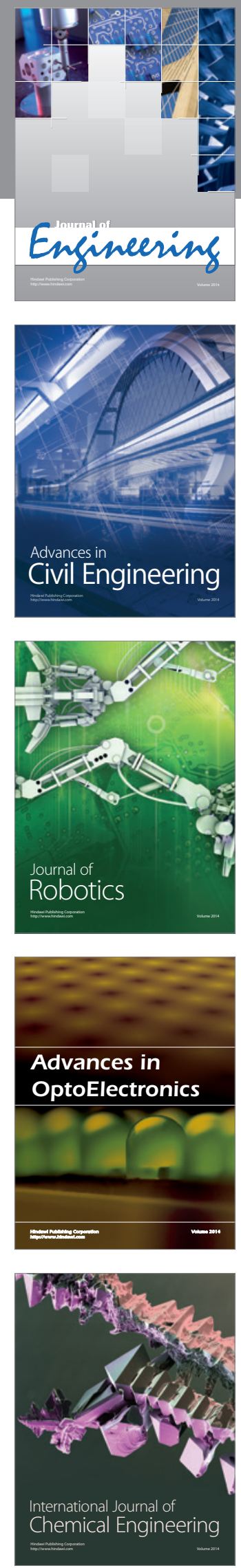

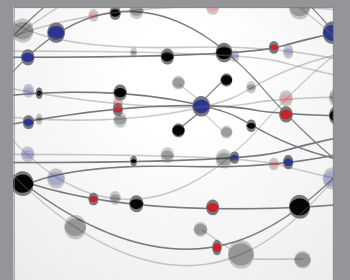

The Scientific World Journal
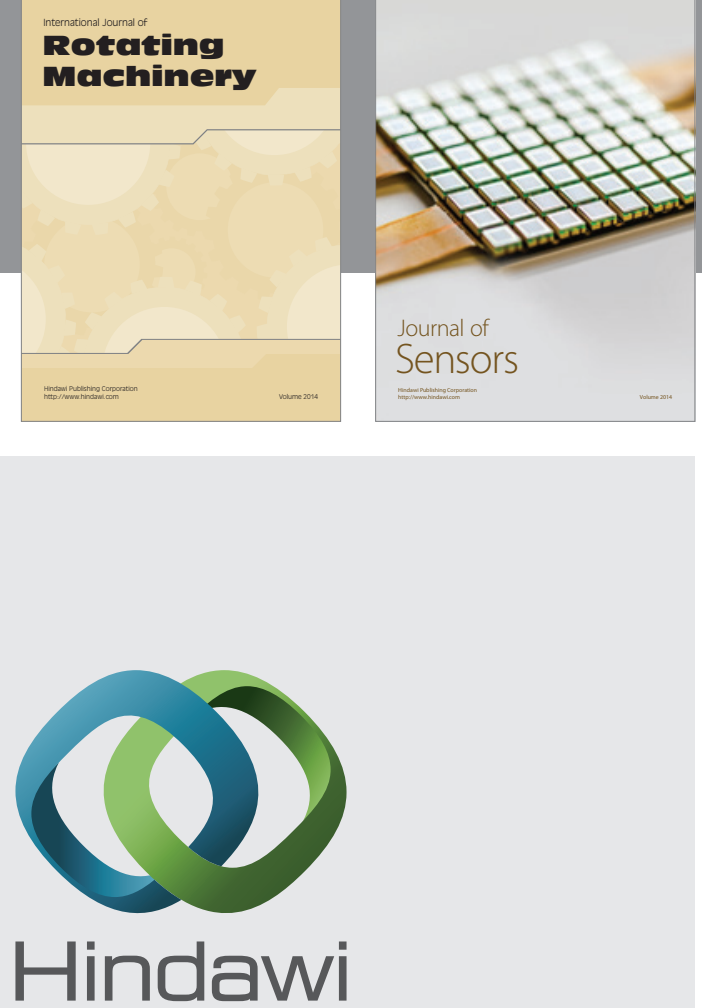

Submit your manuscripts at http://www.hindawi.com
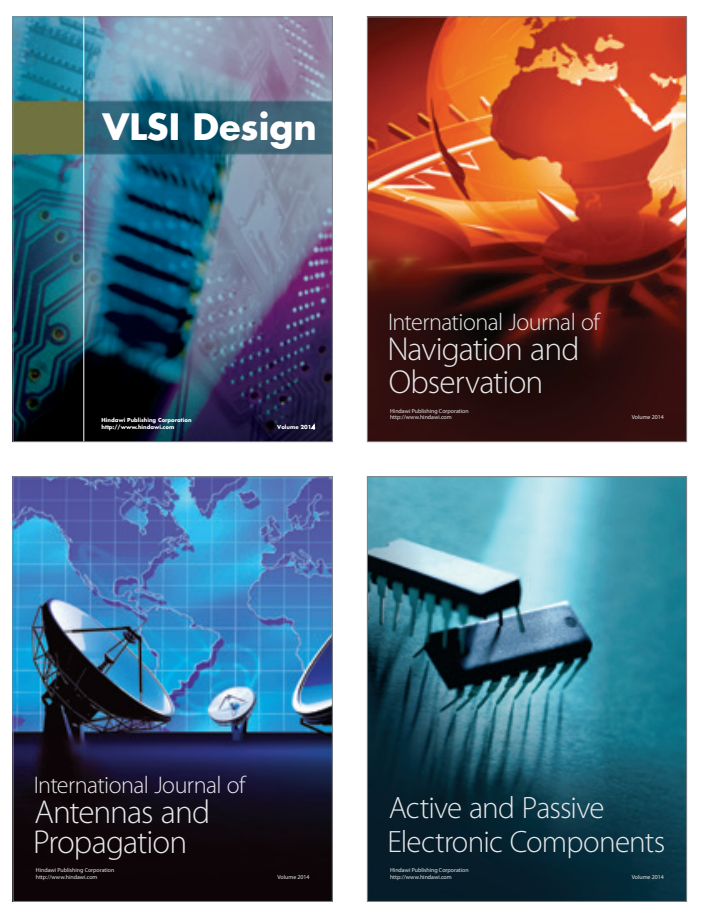
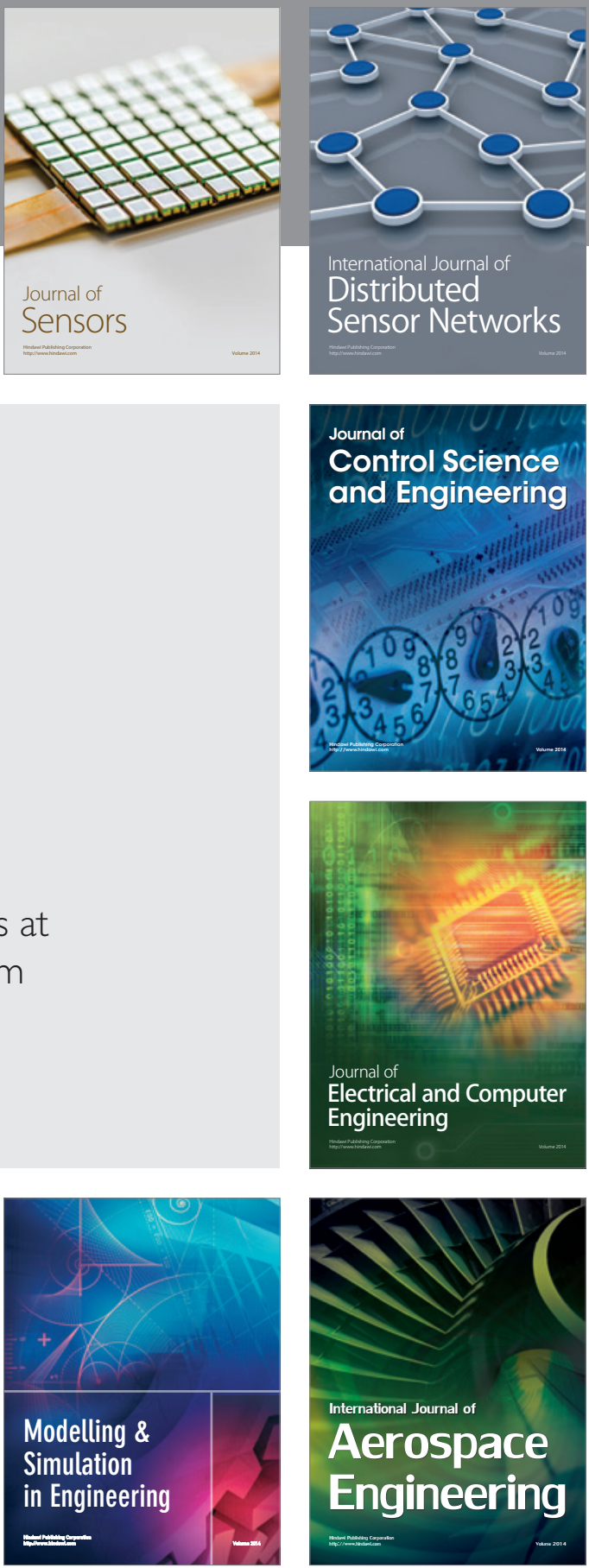

Journal of

Control Science

and Engineering
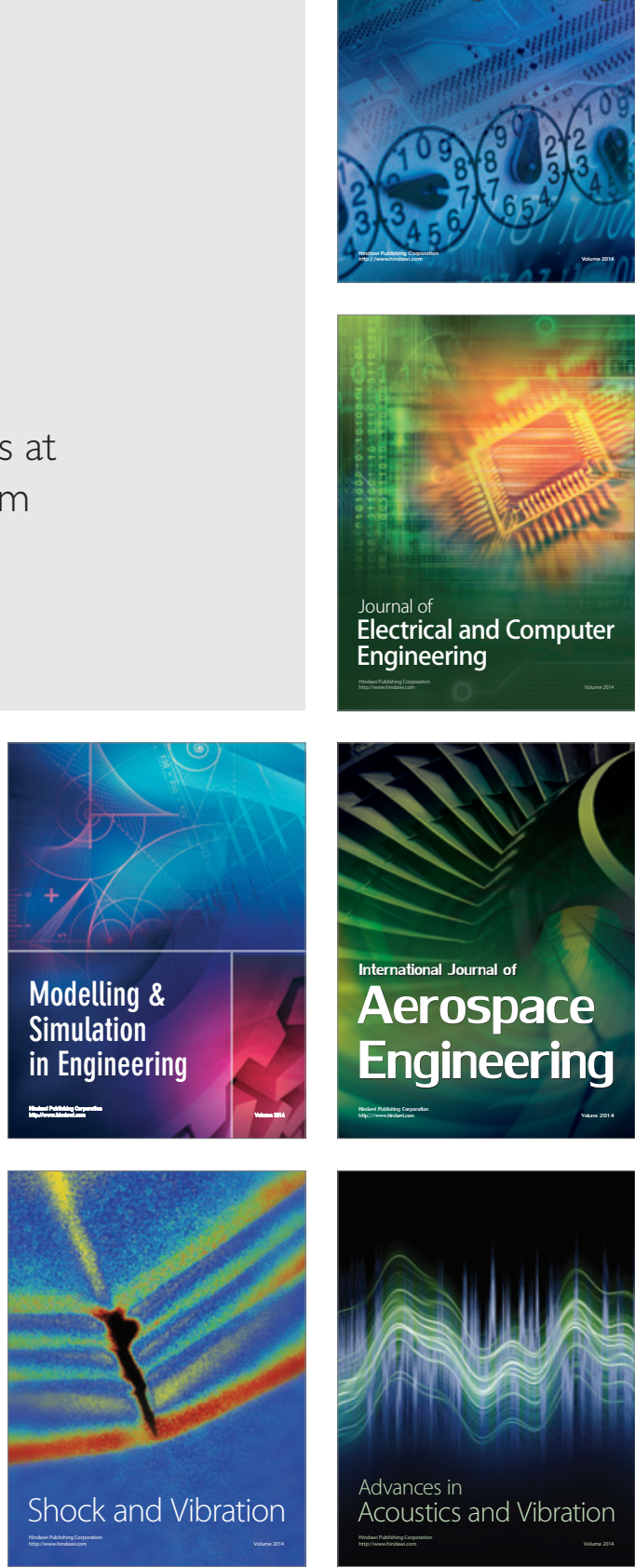